\title{
PROCESOS INFLAMATORIOS DEL TEJIDO ADIPOSO INTRAABDOMINAL, CAUSA NO QUIRURGICA DE DOLOR ABDOMINAL AGUDO: HALLAZGOS EN TOMOGRAFIA COMPUTADA
}

\author{
Drs. Cristián Varela $U^{(1)}$, Miguel Fuentes $V^{(2)}$, Rosario Rivadeneira $H^{(3)}$.
}

1. Departamento de Radiología Clínica Dávila. Departamento de Imágenes Clínica Alemana.

2. Becado de Radiología, Facultad de Medicina Universidad de Chile. Servicio de Radiología Hospital San Borja-Arriarán.

3. Interna. Facultad de Medicina Universidad de los Andes.

\begin{abstract}
Inflammatory alterations of the intraabdominal fatty tissues such as apppendagitis epiploic, segmental infarction of the ometun and mesenteric panniculitis are causes of acute abdominal pain and generally diagnosed clinically as having other processes that need surgical resolution.

We think the computed tomography (CT) as the primary tool for diagnosis.

Our purpose is review the clinical and CT findings in these entities as an aid to radiologists to recognize them.

Key words: Acute abdominal pain, Appendagitis epiploic, Intraabdominal fatty tissues, Mesenteric panniculitis, Omental infarction.
\end{abstract}

Resumen: La apendagitis epiploica, el infarto segmentario del omento mayor y la paniculitis mesentérica son procesos inflamatorios originados en el tejido adiposo intraabdominal, cuya presentación clínica, caracterizada por dolor abdominal agudo, puede simular un cuadro quirúrgico. Rara vez se plantea la sospecha clínica y pensamos que la tomografía computada (TC) es

Varela C. y cols. Procesos inflamatorios del tejido adiposo intraabdominal, causa no quirúrgica de dolor abdominal agudo: Hallazgos en tomografía computada. Rev Chil Radiol 2004; 10: 28-34.

Correspondencia: Dr. Cristián Varela U.

E-mail:cvarela@davila.cl el examen de elección, ya que permite visualizar estas estructuras y descartar otras causas del dolor.

Los apéndices epiploicos son estructuras pedunculadas que protruyen de la superficie serosa del colon. Normalmente no son visibles en estudios de imagen y se confunden con el tejido adiposo intraabdominal. Se hacen evidentes cuando sufren algún proceso patológico o bien cuando existe ascitis, hemoperitoneo o se inyecta medio de contraste intraperitoneal. El hallazgo característico en TC es una imagen redondeada u ovoídea de densidad grasa dependiente de la serosa de algún segmento del colon.

El infarto segmentario del omento mayor es una causa rara de abdomen agudo. En TC se observa una masa de tejido adiposo denso, mal delimitada, con imágenes lineales finas en su espesor y no depende de la serosa del colon.

La paniculitis mesentérica es un proceso inflamatorio que afecta al tejido adiposo de la raíz del mesenterio. En TC su aspecto es inespecífico aunque puede presentarse como un «mesenterio nebuloso». Su diagnóstico es esencialmente de descarte.

Revisamos las manifestaciones clínicas e imagenológicas con énfasis en TC.

Palabras claves: Apendagitis epiploica, Dolor abdominal agudo, Infarto segmentario del omento mayor, Paniculitis mesentérica, TC, Tejido adiposo intraabdominal.

\section{Introducción}

Los procesos inflamatorios originados en el tejido adiposo intraabdominal, tales como la 
apendagitis epiploica, el infarto segmentario del omento mayor y la paniculitis mesentérica, son causa de dolor abdominal agudo, que pueden simular un cuadro de resolución quirúrgica.

Aun cuando infrecuentes, son poco conocidos y rara vez se les sospecha clínicamente, por tanto no se les busca de manera dirigida y su detección solo se hace en el acto quirúrgico.

Aunque pueden ser diagnosticados con ultrasonografía (US), el examen de elección es la tomografía computada (TC), dado su mayor rendimiento diagnóstico que se fundamenta en una mayor capacidad para detectar estas lesiones, especialmente en localizaciones profundas y en individuos obesos. Además, esta técnica es de gran especificidad ya que demuestra el origen de la patología en el tejido adiposo, dada su densidad característica.

Revisaremos las manifestaciones clínicas e imagenológicas de estos procesos en TC.

\section{Apendagitis epiploica}

Los apéndices epiploicos son estructuras pedunculadas que protruyen desde la superficie serosa del colon, en relación con las tenias, hacia la cavidad peritoneal. Consisten en masas de aspecto digitiforme conformadas por tejido adiposo subseroso. En promedio miden de 2 a $5 \mathrm{~cm}$ de longitud y 1 a $2 \mathrm{~cm}$ de grosor, aunque se han reportado casos de hasta $15 \mathrm{~cm}$ de longitud. Se extienden desde el ciego hasta la unión rectosigmoídea en un número de 100 a 150, siendo más numerosos y de mayor volumen los localizados en colon descendente y sigmoides. Lo anterior explica porque las manifestaciones clínicas tienden a presentarse con mayor frecuencia a izquierda.

Se desconoce su función exacta. Al respecto se postulan varias teorías, entre ellas que pueden servir como apoyo a las paredes del colon durante la peristalsis, como reservorio de sangre cuando el colon y sus vasos intramurales están contraídos, como depósito energético y como epiplón frente a procesos inflamatorios ${ }^{(1-2)}$.

Cada apéndice epiploico es irrigado por una o dos pequeñas arteriolas, ramas de los vasos rectos del colon y drenan por venas únicas que pasan a través de un pedículo estrecho. Esta conformación anatómica, pediculada, con gran movilidad e irrigación terminal, los hace propensos a la torsión y trombosis con el consecuente infarto hemorrágico ${ }^{(1,3)}$.

En condiciones normales los apéndices epiploicos no se visualizan en estudios imagenológicos ya que se confunden con el tejido adiposo intraabdominal. Estas estructuras se hacen evidentes cuando sufren algún proceso patológico o bien cuando existe ascitis, hemoperitoneo o se inyecta medio de contraste intraperitoneal (Figura 1).

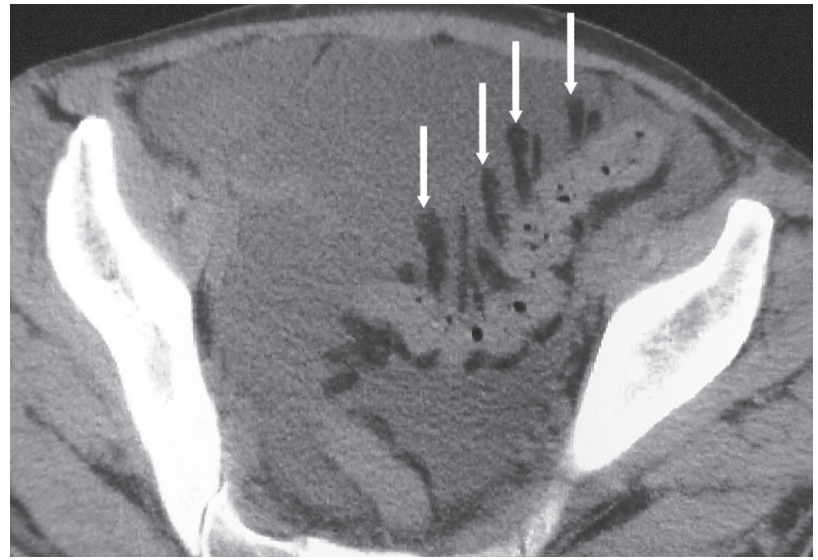

Figura 1. Apéndices epiploicos normales en un paciente con ascitis. Se identifican numerosas estructuras hipodensas, de aspecto digitiforme (flechas), en estrecho contacto con la pared del colon y que parecen «flotar» en el líquido ascítico.

La apendagitis epiploica primaria es un proceso inflamatorio de origen vascular, secundario a torsión o a trombosis de la vena de drenaje ${ }^{(1)}$.

Como factores de riesgo se cita a la obesidad o el sobrepeso, que aumentan el tamaño de estas estructuras, la actividad física extenuante con la consiguiente mayor movilidad que haría posible una torsión y a las comidas abundantes que pueden determinar una ectasia venosa esplácnica y trombosis.

La apendagitis epiploica secundaria se refiere a la participación de estas estructuras en procesos de vecindad, cumpliendo su función de epiplón al intentar limitar la diseminación de un foco inflamatorio. Es más frecuente que la apendagitis primaria y su causa más prevalente es la diverticulitis de colon (Figura 2).

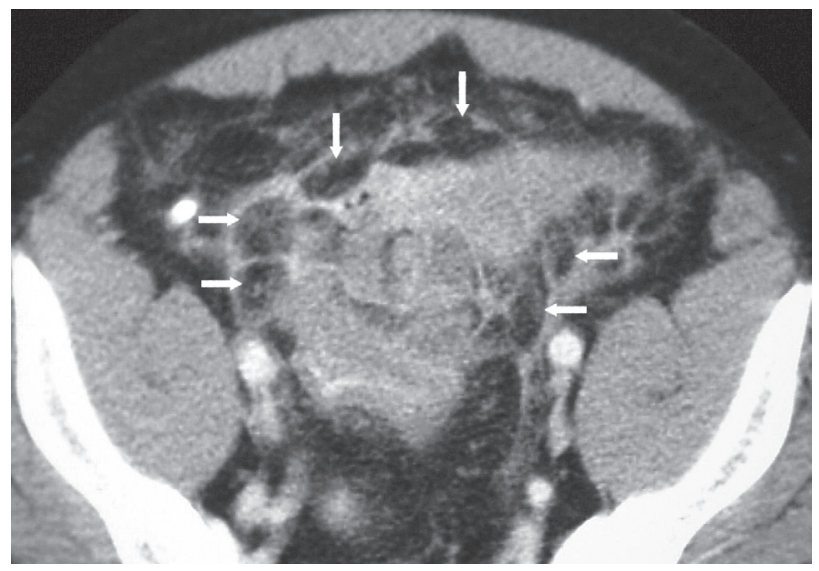

Figura 2. Apendagitis epiploica secundaria a una diverticulitis complicada del colon sigmoides. Se observan múltiples imágenes ovoides con densidad grasa (flechas), adyacentes a cambios inflamatorios pericólicos. 
La apendagitis epiploica primaria se puede manifestar a cualquier edad, incluso se ha descrito en niños, no obstante es más común en adultos jóvenes. No tiene un claro predominio por sexo(2).

Se le considera una patología infrecuente e históricamente se la diagnosticaba durante una laparotomía exploradora. En los últimos años se ha observado una mayor incidencia dado el gran desarrollo de los métodos de imágenes y su aplicación masiva en el estudio del dolor abdominal agudo.

El cuadro clínico es relativamente característico. El síntoma principal consiste en dolor abdominal de inicio súbito, relativamente intenso y localizado, generalmente en el flanco o la fosa ilíaca izquierda. Se puede acompañar, en algunos casos, de náuseas y distensión abdominal pero sin compromiso del estado general ni anorexia. No se describen vómitos importantes ni alteración del tránsito intestinal ${ }^{(1-3)} \mathrm{Al}$ examen físico destaca dolor localizado y preciso a la palpación de tal modo que el paciente lo indica con el dedo. Ocasionalmente existe signo del rebote. A veces es posible palpar una pequeña masa o zona empastada en el flanco o fosa ilíaca ${ }^{(1,2)}$. Los exámenes de laboratorio en general son normales pero puede haber leve elevación de los leucocitos y de la proteína $C$ reactiva.

A veces el cuadro clínico es inespecífico y puede simular un proceso de resolución quirúrgica, especialmente apendicitis aguda a derecha y diverticulitis a izquierda.

De acuerdo a nuestra experiencia, rara vez se plantea la sospecha clínica de esta patología y su diagnóstico constituye una sorpresa para el médico clínico. La confirmación diagnóstica debe efectuarse con estudios imagenológicos orientados principalmente a descartar otras causas más frecuentes de dolor abdominal agudo.

El manejo de esta patología es fundamentalmente médico y consiste en medidas generales como reposo, analgesia y régimen liviano. El tratamiento quirúrgico está reservado para el fracaso del manejo médico o frente a las complicaciones.

Tomografía Computada: Si bien la US puede ser diagnóstica, el examen de elección es la TC de abdomen y pelvis la cual permite un diagnóstico específico y definitivo ${ }^{(1-4)}$ demostrando que el proceso se origina en uno o en un grupo de apéndices epiploicos e indicando su exacta localización, extensión y presencia de complicaciones. A pesar de que no es indispensable el uso de contraste oral o intravenoso para la detección y caracterización de estas lesiones, se recomienda su utilización ya que permite descartar otras causas de dolor abdominal.

El hallazgo más importante en TC es la presencia de una imagen redondeada u ovoidea de densidad grasa dependiente de la serosa de algún segmento del colon. El apéndice epiploico afectado se encuentra marginado por una fina imagen lineal de aproximadamente $1 \mathrm{a} 2 \mathrm{~mm}$ de grosor que representa la serosa engrosada. En las vecindades existe un halo de tejido adiposo denso en forma de estrías o bandas y también se puede observar engrosamiento del peritoneo parietal adyacente e incluso de la pared abdominal anterior (Figura 3). Un signo clave es la demostración de la dependencia del proceso de la pared del colon que muchas veces aparecerá engrosada en el sitio de implantación del apéndice epiploico (Figura 4).

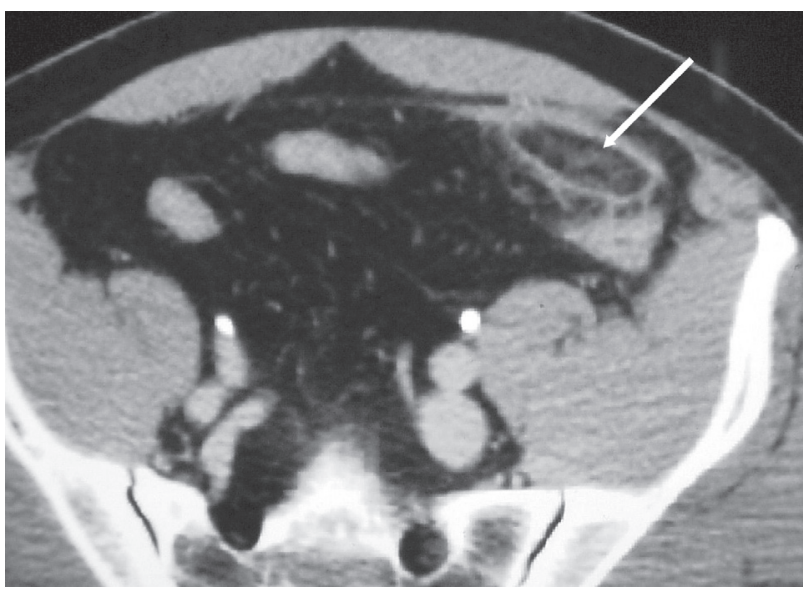

Figura 3. Apéndice epiploico inflamado en fosa ilíaca izquierda, donde se observa una imagen ovoide con densidad grasa (flecha), marginado por una fina imagen lineal, que representa la serosa engrosada, y rodeada por un halo hiperdenso de tejido adiposo adyacente. La imagen lineal densa, anterior y medial al apéndice epiploico, corresponde a peritoneo parietal inflamado.

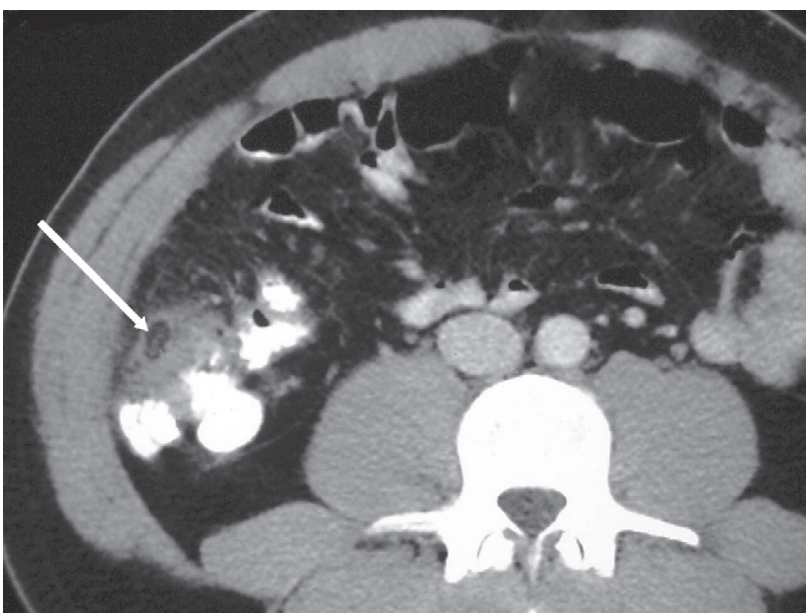

Figura 4. Apéndice epiploico inflamado en flanco derecho dependiente de la pared anterior del colon ascendente, se observa una imagen ovoide, con densidad grasa, (flecha). Nótese el significativo engrosamiento de la pared anterior del colon ascendente, hallazgo clave para diferenciar esta patología del infarto segmentario del omento mayor. 
En general, el proceso afecta a un apéndice epiploico, pero puede comprometer un grupo de ellos (Figura 5). Cuando el proceso es subagudo y en especial, si existe infarto del o de los apéndices epiploicos, las manifestaciones a la TC pueden ser atípicas, observándose una imagen densa con escaso o nula cantidad de tejido de densidad grasa. En este caso la localización y la íntima relación con las paredes del colon son las que orientan el diagnóstico (Figura 6).

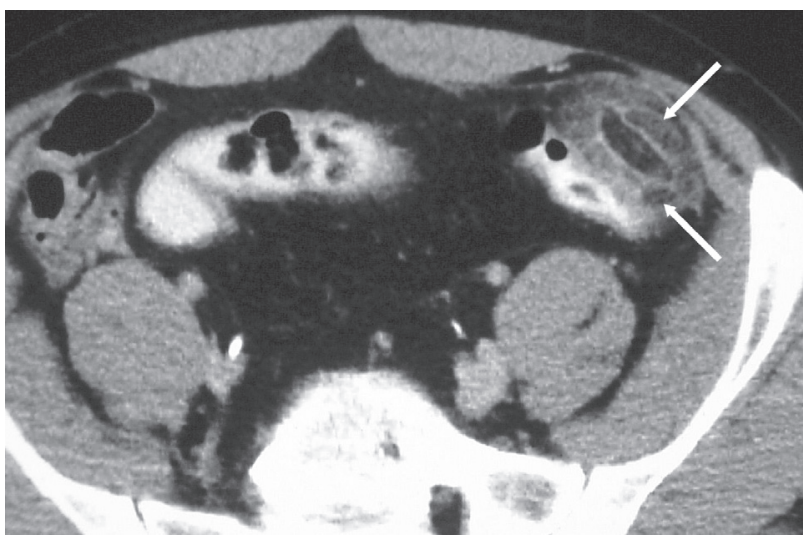

Figura 5. Múltiples apéndices epiploicos inflamados en relación a un segmento del colon descendente (flechas), se observan como un grupo de estructuras ovoides $y$ redondeadas con densidad grasa. Nótese la íntima relación con el colon, cuya pared anterior está levemente engrosada. También existe engrosamiento del peritoneo parietal, visible como una imagen lineal, anterior a los apéndices epiploicos.

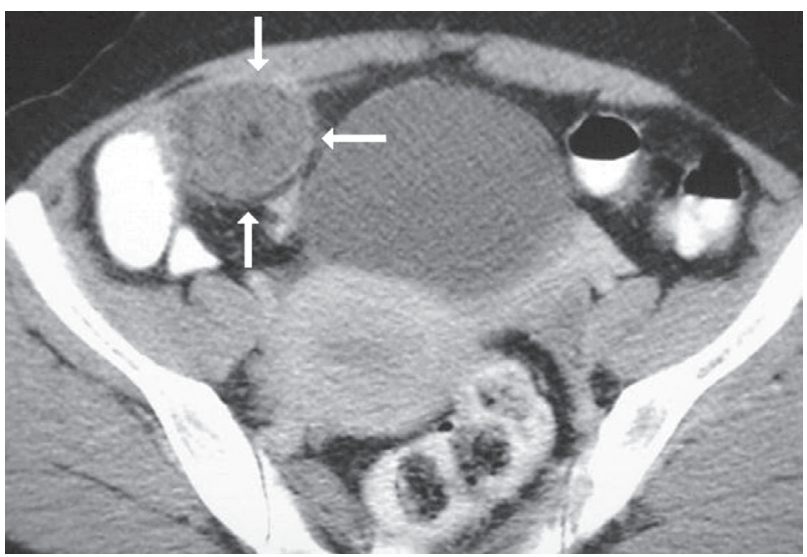

Figura 6. En fosa ilíaca derecha se observa una masa redondeada, medial al ciego, con una densidad heterogénea y algunas pequeñas áreas puntiformes con densidad grasa. Está rodeada por una imagen densa de aspecto capsular. El borde lateral de la lesión tiene íntima relación con las paredes del colón, las que aparecen levemente engrosadas, hallazgo clave para plantear el diagnóstico de apendagitis epiploica atípica, dada su escasa densidad grasa debido a cambios inflamatorioisquémicos avanzados. El estudio patológico demostró un conjunto de apéndices epiploicos infartados.
Los hallazgos en TC de un apéndice epiploico inflamado pueden persistir incluso después de 19 semanas desde su diagnóstico ${ }^{(3)}$. En la evolución se observa una disminución progresiva del diámetro y densidad de la lesión, habiendo recuperación de la densidad de la grasa que rodea al apéndice afectado. En algunos casos finalmente, puede llegar a la calcificación (Figuras 7, 8).
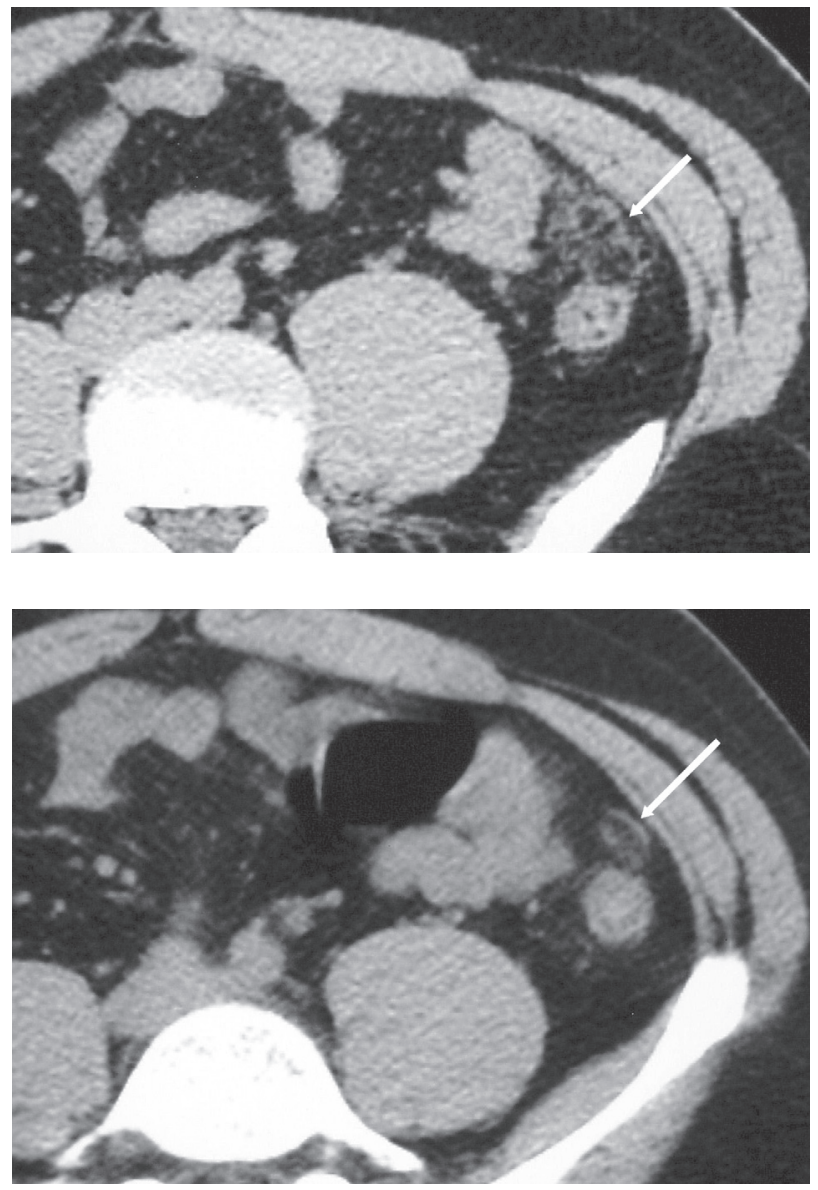

Figura 7 a,b. Apéndice epiploico inflamado, evolución. a: Se observa una imagen ovoide con densidad grasa, dependiente de la pared anterior del colon descendente (flecha). b: Control cuatro semanas después, la lesión ha disminuido de tamaño, sus contornos están más definidos y existe regresión completa de los cambios inflamatorios adyacentes (flecha).

Otros métodos de imágenes útiles para el diagnóstico son la US y la resonancia magnética $(\mathrm{RM})$. La US puede ser un excelente método diagnóstico ${ }^{(1-4)}$, sin embargo, es un examen operador y equipo dependiente, posee menor rendimiento en pacientes obesos o localizaciones profundas. Adicionalmente, pueden existir dificultades en demostrar la relación del proceso con el colon o en caracterizarlo como originado en el tejido adiposo. La RM es indudablemente un excelente método para demostrar la apendagitis epiploica dada su gran 


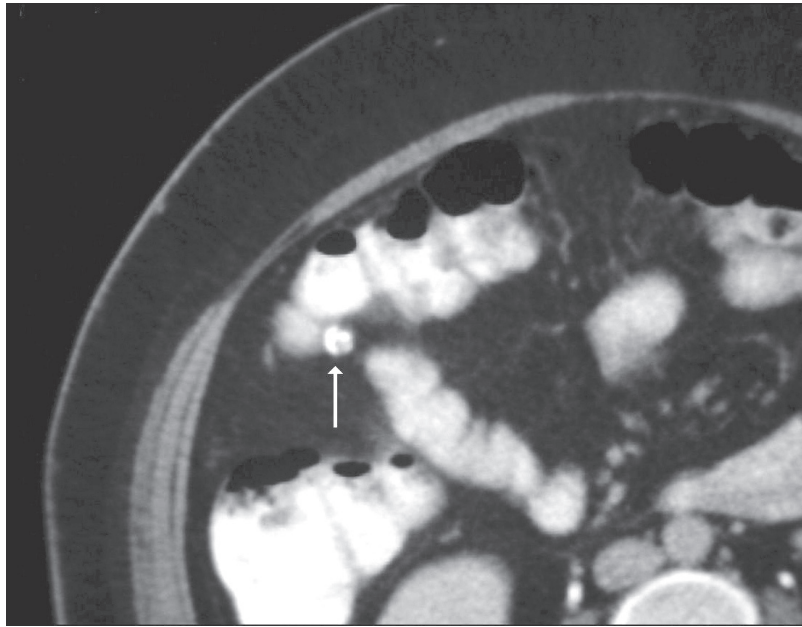

Figura 8. Apendagitis epiploica, evolución. Control un año después de un episodio de apendagitis epiploica dependiente del colon transverso. Se observa calcificación puntiforme (flecha) pericólica secuela del proceso inflamatorio.

resolución de partes blandas y la señal característica del tejido adiposo, méritos comparables a la TC. Está limitada por su costo y menor disponibilidad.

El pronóstico de esta patología es excelente y de rápida recuperación con terapia simple y conservadora. Las complicaciones son muy raras y consisten en compresión extrínseca del colon adyacente con estenosis que puede llegar a la obstrucción. Aun más raras son la invaginación o la perforación (Figura 9).

\section{Infarto segmentario del omento mayor}

El omento o epiplón mayor corresponde a un repliegue del peritoneo compuesto por cuatro capas. Se origina de la curvatura mayor del estómago y cuelga hacia caudal, por delante del colon transverso y del intestino delgado. Está compuesto por cantidades variables de tejido adiposo y su función es limitar la diseminación de procesos infecciosos o inflamatorios.

El infarto segmentario del omento mayor es una causa rara pero conocida de abdomen agudo ${ }^{(5)}$. El origen de este trastorno es desconocido. Esta condición parece ser secundaria a una irrigación anómala o frágil, lo que suele afectar con mayor frecuencia a la mitad derecha de esta estructura. Se produce una necrosis aséptica de un segmento variable del omento mayor, lo que genera un proceso inflamatorio, que con frecuencia afecta el peritoneo parietal anterior e incluso la pared abdominal (Figuras $10 \mathrm{a}, \mathrm{b})$.

Al igual que en el caso de la apendagitis epiploica, el ejercicio extenuante y las comidas abundantes han sido identificados como factores de riesgo para desencadenar el proceso.
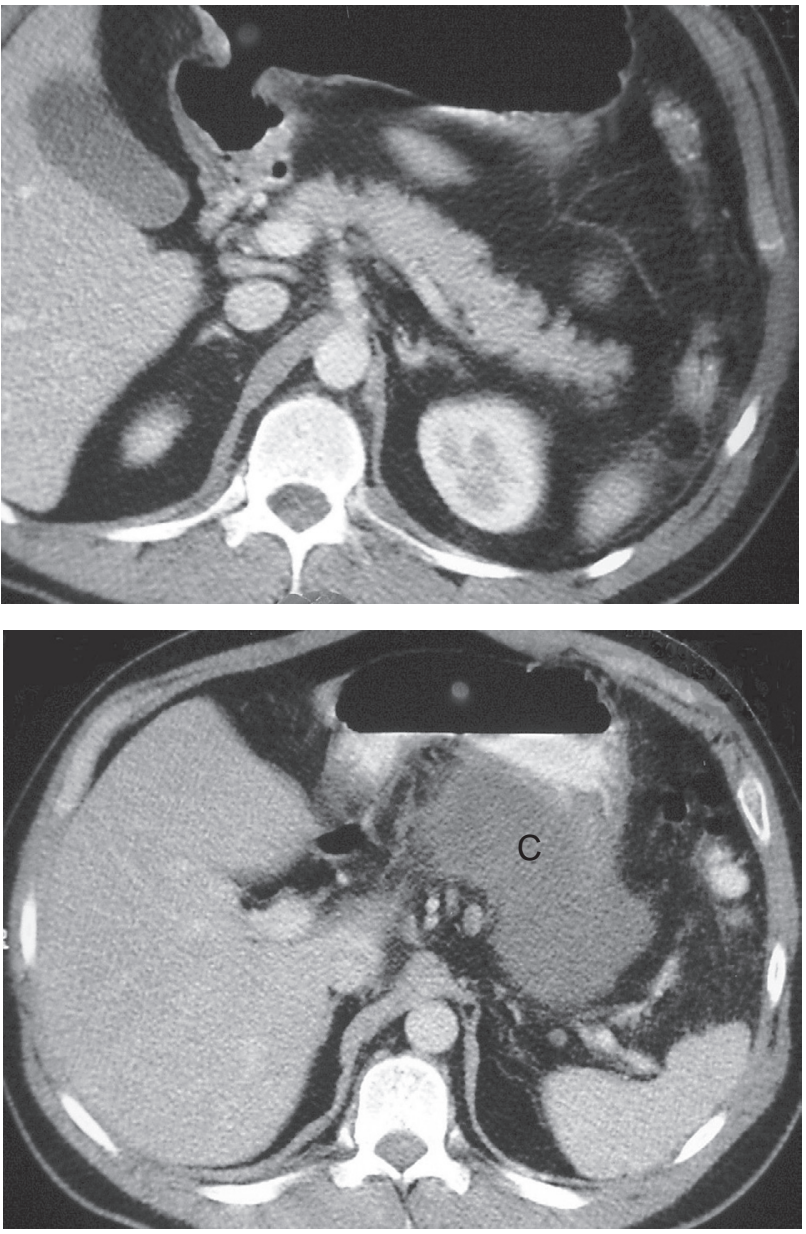

Figura 9 a,b. Apendagitis epiploica, complicación. a: TC de ingreso de un paciente con dolor en hipocondrio izquierdo que muestra una apendagitis epiploica dependiente del ángulo esplénico del colon b: Control. 72 horas después, con el paciente en peor condición clínica. La TC muestra persistencia del proceso y la aparición de una colección de densidad líquida en el saco menor(C). Intraoperatoriamente se demostró la presencia de una perforación del colon en el sitio de implantación del apéndice inflamado.

El infarto puede afectar a pacientes de cualquier edad, incluso niños, pero también es más frecuente en el adulto joven ${ }^{(5)}$.

Tanto el grupo etario como el cuadro clínico y laboratorio son similares a los descritos en la apendagitis epiploica, pero como en este caso se tiende a afectar preferentemente la mitad derecha del omento mayor, con mayor frecuencia el dolor abdominal se encuentra localizado en este lado.

Tomografía Computada: En TC se observa una masa de tejido adiposo denso, mal delimitada, con imágenes lineales finas en su espesor. En general, es de mayor tamaño a las lesiones descritas en la apendagitis epiploica. Su extensión también es mayor y un elemento clave para su diagnóstico es que no se observa dependencia con las paredes del colon (Figura 11). La lesión se localiza en la región 

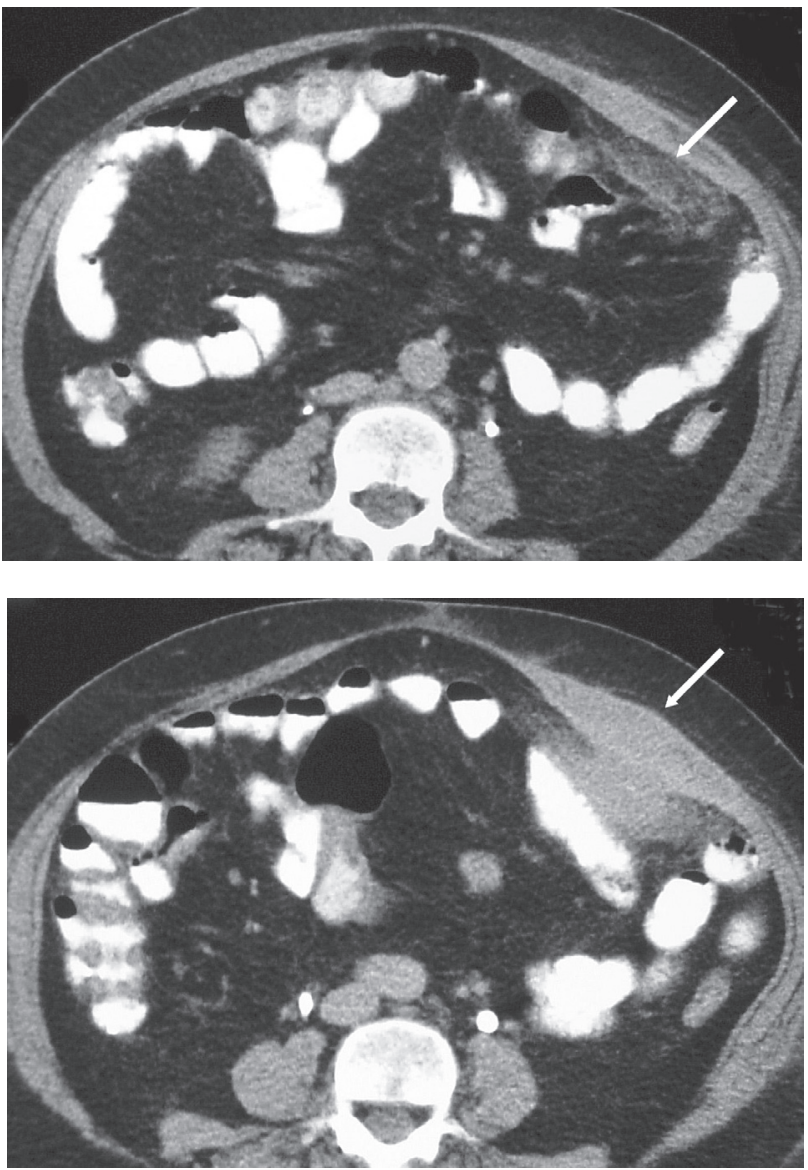

Figura 10 a,b. Infarto segmentario del omento mayor. a: En el flanco izquierdo se observa un aumento de la densidad del tejido adiposo del omento mayor, que en algunas áreas presenta una densidad casi sólida (flecha). b: Esta lesión es extensa y se acompaña de aumento de volumen y densidad del plano muscular de la pared abdominal (flecha).

anterolateral del abdomen, en el sector esperado para el omento mayor e inmediatamente por debajo del peritoneo parietal.

El pronóstico y manejo de esta patología es idéntico al de la apendagitis epiploica. Las complicaciones son muy raras.

\section{Paniculitis mesentérica}

La paniculitis mesentérica es un proceso inflamatorio de origen desconocido, que afecta al tejido adiposo contenido en la raíz del mesenterio. Es una patología de baja frecuencia que puede manifestarse con dolor abdominal agudo.

Existen formas de presentación subaguda o crónica, donde predomina la fibrosis sobre el proceso inflamatorio. Esto se conoce como mesenteritis retráctil. En este caso, se observa una masa sólida en la raíz del mesenterio, la que puede contener calcificaciones y se acompaña de engrosamiento de los tractos vasculares y de las paredes de las asas intestinales adyacentes, las que aparecen

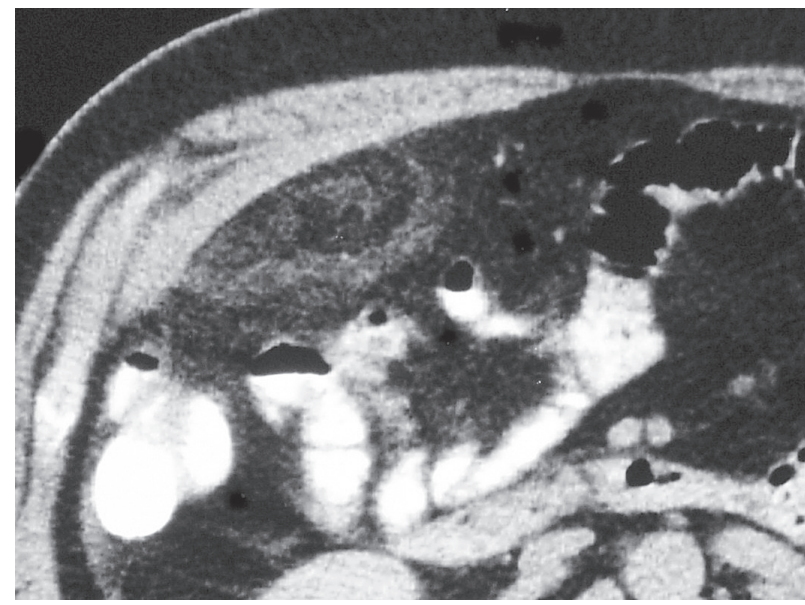

Figura 11. Infarto segmentario del omento mayor En el flanco derecho, en situación anterior, inmediatamente por debajo del peritoneo parietal, existe un aumento de la densidad focal del tejido adiposo. Nótese que no existe relación con el colon ascendente, que presenta paredes de grosor normal.

aglomeradas o incluso «acodadas». Esta forma de enfermedad también presenta un diagnóstico diferencial relativamente amplio y ocasionalmente puede simular otros procesos inflamatorios crónicos, como la fibrosis retroperitoneal o neoplásicos, como el tumor carcinoide ${ }^{(6,7)}$ (Figuras 12, 13).

Tomografía Computada: En la TC se observa un aumento de la densidad del tejido adiposo del mesenterio que tiende a rodear a los vasos sanguíneos que transcurren por él. Puede estar circunscrita por una fina imagen lineal o pseudocápsula. Este aspecto ha sido denominado

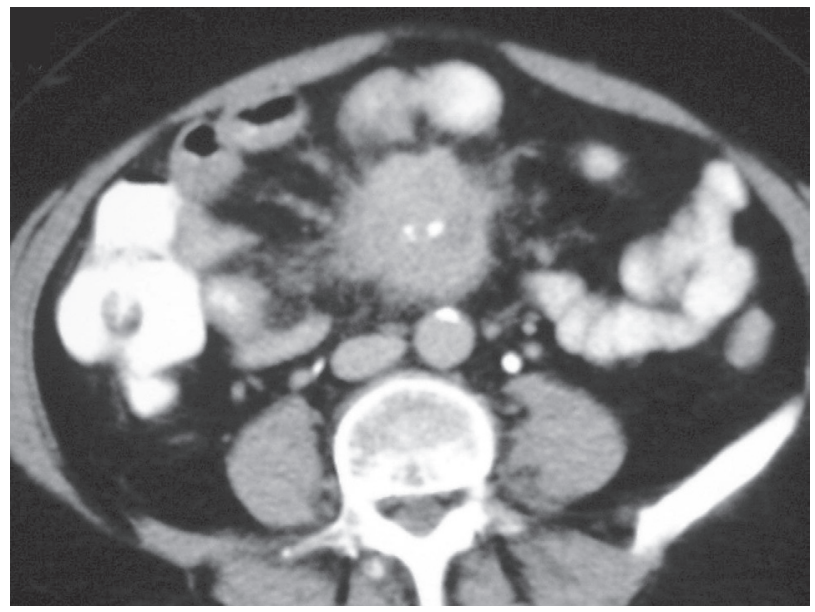

Figura 12. Mesenteritis retráctil. Existe una masa con densidad de partes blandas, de aspecto infiltrativo, que afecta la raíz del mesenterio y rodea la arteria mesentérica superior. Estos hallazgos son inespecíficos y también pueden observarse en neoplasias o en cuadros inflamatorio-fibrosos, como en la extensión de una fibrosis retroperitoneal a la raíz del mesenterio. 


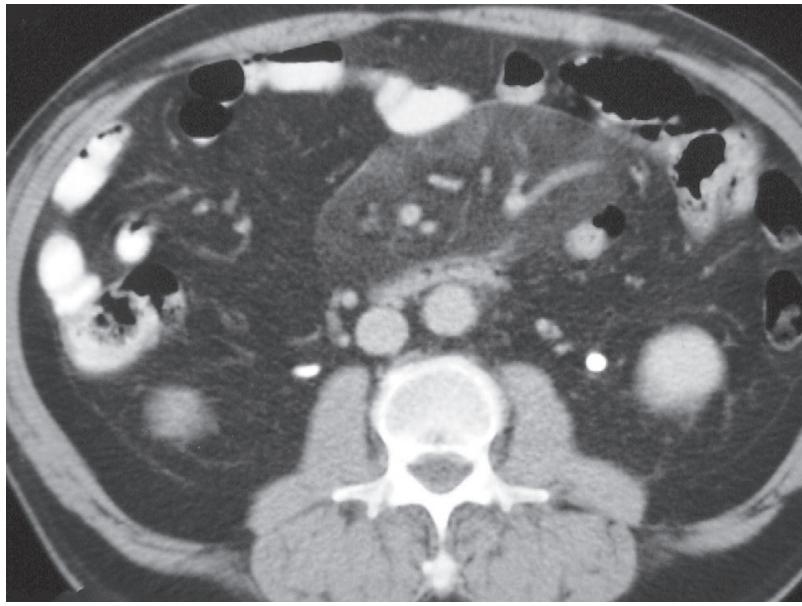

Figura 13. En el espesor del tejido adiposo del mesenterio, se identifica una masa con densidad de partes blandas, homogénea, de contornos espiculados y radiados, con calcificaciones. Como primera posibilidad diagnóstica se planteó un tumor carcinoide. El estudio histológico demostró una mesenteritis retráctil.

«mesenterio nebuloso»(8) (Figura 14). Aunque el aspecto en TC de este proceso es inespecífico y puede ser determinado por un conjunto de otras enfermedades, la presentación de dolor abdominal agudo en ausencia de otros factores de riesgo o de enfermedad preexistente son orientadores. En general, se trata de un diagnóstico de exclusión.

Su pronóstico es bueno para la enfermedad aguda y puede ser pésimo en casos de mesenteritis retráctil grave con oclusión o isquemia intestinal. El manejo es médico, sintomático. El control de la forma aguda debe ser estricto hasta su resolución, dada la posibilidad de evolución hacia formas subagudas 0 crónicas.

\section{Conclusión}

La apendagitis epiploica, el infarto segmentario del omento mayor y la paniculitis mesentérica, procesos inflamatorios originados en el tejido adiposo intraabdominal, con presentación clínica, caracterizada por dolor abdominal agudo y simuladores de un cuadro de resolución quirúrgica pueden ser bien estudiados con TC como examen de elección.

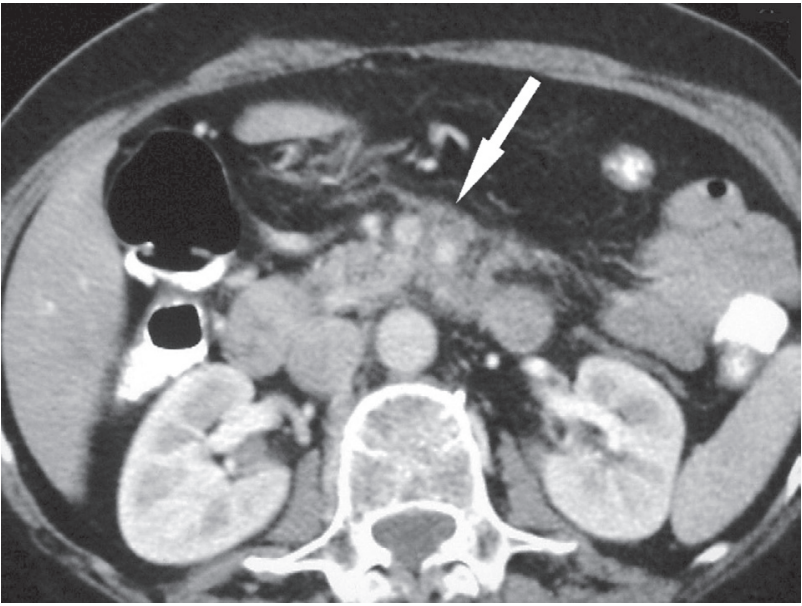

Figura 14. Hallazgos compatibles con una paniculitis mesentérica Se observa un significativo aumento de la densidad del tejido adiposo mesentérico, que rodea los vasos que transcurren por él, marginado por una fina imagen de aspecto capsular (flecha).

\section{Bibliografía}

1. Ghahremani G.G, White E.M, Hoff F.L, et al. Appendices Epiploicae of the Colon: radiologic and pathologic features. Radiographics 1992; 12: 59-77.

2. Horvath E, Majlis S, Seguel S. y col. Apendicitis epiploica primaria: Diagnóstico clínico y radiológico. Rev Med Chile 2000; 128: 601-607.

3. Rao P.M, Wittenberg J, Lawrason J.N. Primary epiploic appendagitis: Evolutionary changes in CT appearance. Radiology 1997; 204: 713-717.

4. Rioux M, Langis P. Primary epiploic appendagitis: Clinical, US and CT findings in 14 cases. Radiology 1994; 191:523526.

5. Puylaert J.B. Right sided segmental infarction of the omentum: Clinical, US and CT findings. Radiology 1992;185:169-172.

6. Hamrick-Turner J.E, Chiechi M.V. Neoplastic and inflammatory processes of the peritoneum, omentum and mesentery: Diagnosis with CT. Radiographics 1992; 12:1051-1068.

7. Sheth S, Horton K.M, Garland M.R, Fishman E. Mesenteric neoplasms:CT Appearance of primary and secondary tumors and differential diagnosis. Radiographics 2003;23: 457-473.

8. Mindelzun R.E, Jeffrey R.B, Lane M.J, Silverman P.M. The Misty Mesentery on CT: Differential Diagnosis. AJR 1996;167:61-65. 